\title{
Avaliação das propriedades do biopolímero polihidroxibutirato (PHB) extraído por vermes de Zophobas morio Fabricius
}

\author{
Evaluation of the properties of the polymer \\ polyhydroxybutyrate (PHB) extracted from \\ Zophobas morio Fabricius worms
}

\author{
Luana Orlandi de Aguiar ${ }^{1}$, Natalício Stachewski ${ }^{2}$, Michele Cristina Formolo Garcia ${ }^{1,2}$, \\ Ana Paula Kurek ${ }^{3}$, Andrea Lima dos Santos Schneider ${ }^{1,2}$, \\ Denise Monique Dubet da Silva Mouga ${ }^{2}$, Ana Paula Testa Pezzin ${ }^{3}$
}

\footnotetext{
${ }^{1}$ Curso de Engenharia Química, Universidade da Região de Joinville - UNIVILLE, Rua Paulo Malschitzki 10. Zona Industrial. CEP:89.201-974, Joinville, SC, Brasil.

${ }^{2}$ Curso de Ciências Biológicas, Universidade da Região de Joinville - UNIVILLE, Rua Paulo Malschitzki 10. Zona Industrial. CEP:89.201-974, Joinville, SC, Brasil.

${ }^{3}$ Mestrado em Engenharia de Processos, Universidade da Região de Joinville - UNIVILLE. Rua Paulo Malschitzki 10, Zona Industrial, CEP: 89.201-974, Joinville, SC, Brasil.

e-mail: anapezzin@yahoo.com.br
}

\section{RESUMO}

Polihidroxibutirato (PHB) é um biopolímero produzido intracelularmente e acumulado como reserva de energia por muitos microrganismos, sendo o principal, a bactéria Cupriavidus necator. Logo, é necessário realizar a extração dos grânulos intracelulares do interior das células. A extração química do PHB com clorofórmio e hipoclorito de sódio é eficiente, porém, utilizam-se elevadas quantidades de clorofórmio, solvente tóxico e volátil. Assim, faz-se necessário o estudo de novas tecnologias para a extração do PHB, buscando tornar o processo viável tecnologicamente, visto que este biopolímero é um importante candidato para substituição de polipropileno (PP). Diante desse contexto, este trabalho objetivou avaliar o processo de extração do PHB por meio das larvas de Zophobas morio Fabricius, comparado ao processo químico tradicional. O PHB foi sintetizado pela bactéria Cupriavidus necator em frascos de Erlenmeyer com $300 \mathrm{~mL}$ de meio mineral contendo glicose e frutose como fontes de carbono. $\mathrm{O}$ cultivo foi conduzido por $24 \mathrm{~h}$ a $30{ }^{\circ} \mathrm{C}$ e $150 \mathrm{rpm}$. A biomassa obtida do cultivo foi submetida à extração química (dispersão de clorofórmio/hipoclorito de sódio) e biológica, sendo, para isto, utilizada em uma mistura 2:1 (m/m) de farelo de trigo para biomassa úmida contendo PHB como fonte de alimentação das larvas de Zophobas morio Fabricius. O PHB obtido pelos dois processos foi caracterizado por termogravimetria (TG), calorimetria diferencial exploratória (DSC), espectroscopia na região do infravermelho com transformada de Fourier reflexão total atenuada (FTIR/ATR), difratometria de raios-X (DRX) e microscopia eletrônica de varredura (MEV). Verificou-se que a amostra extraída pelo método biológico (PHB_EB), quando comparada com a amostra extraída pelo método químico (PHB_EQ), apresentou a mesma estrutura química e que a metodologia biológica usando larvas apresentou-se mais rápida e eficiente, garantindo a extração do PHB com elevada pureza e estabilidade térmica, com reduzida quantidade de solvente, tornando este processo mais ambientalmente amigável.

Palavras-chave: Extração biológica, Polihidroxibutirato, Zophobas morio Fabricius

\section{ABSTRACT}

Polyhydroxybutyrate (PHB) is an intracellularly produced biopolymer accumulated as an energy reserve by many microorganisms, being the main producer the bacterium Cupriavidus necator. Therefore, it is necessary to extract intracellular granules from the inside of cells. PHB chemical extraction with chloroform and sodium hypochlorite is efficient, but high amounts of chloroform, toxic and volatile solvent are used. Thus, it 
is necessary to study new technologies for the extraction of PHB, seeking to make the process technologically, since this biopolymer is an important candidate for polypropylene replacement (PP). In this context, this study aimed to evaluate the PHB extraction process from larvae Zophobas morio Fabricius. PHB was synthesized by the bacterium Cupriavidus necator in Erlenmeyer flascks with $300 \mathrm{~mL}$ of mineral medium containing glucose and fructose as carbon sources. The culture was conducted for $24 \mathrm{~h}$ at $30{ }^{\circ} \mathrm{C}$ and $150 \mathrm{rpm}$. Biomass obtained from cultive was submitted to chemical extraction (dispersion chloroform/sodium hypochlorite) and biological, and for this, used in a mixture $2: 1(\mathrm{~m} / \mathrm{m})$ of the wheat meal with cells containing PHB as a feeding source of the larvae of Zophobas morio Fabricius. PHB obtained by the two recovery processes were characterized by thermogravimetry (TG), exploratory differential calorimetry (DSC), infrared spectroscopy with Fourier transform - total attenuated reflection (FTIR/ATR), Xray diffractometry (XRD) and scanning electron microscopy (SEM). It was found that the sample extracted by the biological method (PHB_EB), when compared with the sample extracted by the chemical method (PHB_EQ), presented the same chemical structure, and that the biological methodology using larvae was faster and more efficient, guaranteeing the extraction PHB with high purity and thermal stability, with reduced amount of solvent, making this process more environmentally friendly.

Keywords: Biological recovery, Polyhydroxybutyrate, Zophobas morio Fabricius

\section{INTRODUÇÃO}

A produção e consumo de polímeros aumenta continuamente, atualmente é impossível imaginar nosso dia a dia sem estes materiais [1]. Os plásticos são consumidos globalmente a um ritmo de cerca de 311 milhões de toneladas por ano, sendo a grande maioria de polímeros petroquímicos [2]. Uma alternativa é a reciclagem, porém apenas uma pequena parcela é reciclada. A maioria dos polímeros petroquímicos acaba sendo destinados a aterros sanitários e industriais ou incinerados, ao fim da sua vida útil, alternativas que ocasionam grandes impactos ambientais devido ao longo tempo de degradação desses materiais no meio ambiente [3].

Alternativamente, surgem os polímeros biodegradáveis como os polihidroxialcanoatos (PHAs), que são poliésteres alifáticos naturais biodegradáveis, sintetizados naturalmente por várias espécies bacterianas como reserva de energia $[4,5]$. As propriedades desses polímeros podem variar de termoplásticos rígidos a elastômeros elásticos, sendo diretamente influenciadas pela escolha do substrato, bactérias e condições de cultivo [6]. Dentre toda a variedade de PHAs existentes, há o polihidroxibutirato (PHB), polihidroxivalerato (PHV) e poli(hidroxibutirato-co-valerato) (PHBV), sendo que o PHB é o mais simples e extensamente estudado [7, 8].

O PHB é um biopolímero cristalino e linear com propriedades estruturais semelhantes ao polipropileno isotático (PP) e apresenta a vantagem de ser biodegradável e biocompatível, sendo um candidato para a substituição do uso do polímero proveniente de fontes fósseis [9, 10]. De acordo com SILVA et al. [11], as aplicações do PHB são destinadas, na sua grande maioria, a produtos elaborados por termoformagem e injeção. Além disso, devido à sua natureza biodegradável e elevadas propriedades mecânicas, o PHB pode ser utilizado na produção de embalagens e itens descartáveis [12]. Também é amplamente estudado para aplicações na área médica, como em fios de suturas, malhas cirúrgicas, curativos e tecidos para regeneração óssea e nervosa, por exemplo [13-15].

A síntese do PHB pode ser realizada por várias bactérias, sendo a espécie mais utilizada a Cupriavidus necator, devido à sua capacidade de acumular o polímero em até $90 \%$ da massa seca de sua célula [16]. Segundo ARAMVASH et al. [17], o acúmulo dos grânulos intracelulares de PHB depende de fatores como $\mathrm{pH}$, aeração, fontes de carbono e nitrogênio e meio de cultura. A síntese do polímero é dividida em duas etapas, na primeira os micro-organismos são induzidos ao crescimento em meio sem limitação de nutrientes e, na segunda etapa, faz-se a limitação dos nutrientes essenciais e excesso de fonte de carbono, promovendo o acúmulo do polímero na forma de grânulos intracelulares como reserva de energia e alimento [11].

Como o polímero é intracelular, após o processo de polimerização, é necessário realizar a extração do mesmo. Segundo JACQUEL et al. [18], os métodos de extração podem ser realizados de diferentes maneiras, como, por exemplo, com o uso de solventes, por perturbação mecânica e métodos biológicos. Conforme o método utilizado, se obtêm diferentes rendimentos e purezas, que podem variar de 60 a $98 \%$. Convencionalmente, a extração é realizada quimicamente utilizando elevadas quantidades de clorofórmio, apresentando elevado custo e problemas do ponto de vista ambiental, visto que esse solvente é altamente tóxico e volátil [19]. Sendo assim, TELLES et al. [20] indicaram a necessidade do desenvolvimento de métodos que sejam viáveis econômica e ambientalmente e que garantam o desenvolvimento de materiais com o máximo possível de pureza e propriedades físicas, mecânicas e químicas adequadas.

Atualmente, há poucos estudos sobre o uso de novas tecnologias biológicas em escala industrial visando 
à redução de custos e troca do emprego de produtos químicos de elevada toxicidade para realizar a extração do polímero do interior das células. Estudos realizados por MURUGAN et al. [1] e ONG et al. [21], verificaram a possibilidade de substituição do uso de solventes para extração dos grânulos intracelulares de PHB pela utilização de larvas do besouro Tenebrio molitor Linnaeus, sendo que esta espécie foi capaz de digerir o material não poliéster, liberando o PHB intacto no resíduo fecal.

Dentre as espécies de besouro pertencentes à família Tenebrionidae da ordem Coleoptera tem-se o Zophobas morio e Tenebrio molitor, conhecidos popularmente como "Tenebrio gigante" e "bicho da farinha", respectivamente [22, 23]. De acordo com YANG et al. [24], essas espécies são capazes de biodegradar polímeros sintéticos em gás carbônico $\left(\mathrm{CO}_{2}\right)$ e água $\left(\mathrm{H}_{2} \mathrm{O}\right)$ e os carbonos dos produtos são transformados em biomassa.

Assim sendo, este trabalho teve como objetivo avaliar o processo de extração do PHB, sintetizado pela bactéria Cupriavidus necator, por meio das larvas de Zophobas morio Fabricius, comparando as alterações no biopolímero ocasionadas pela extração biológica com a extração química como amostra de referência.

\section{MATERIAIS E MÉTODOS}

Neste trabalho, os experimentos foram realizados em etapas, onde primeiramente foi feita a síntese do PHB, e posteriormente a extração química obtendo um filme polimérico e a extração biológica pelas fezes das larvas, sendo as amostras obtidas encaminhadas para as análises de TG, DSC, FTIR/ATR, DRX e MEV. A Figura 1 apresenta o fluxograma experimental detalhado das etapas desenvolvidas neste trabalho, sendo que o tempo do processo de extração pelo método químico levou cerca de $126 \mathrm{~h}$, quando comparado ao método biológico que durou em torno de $111 \mathrm{~h}$.

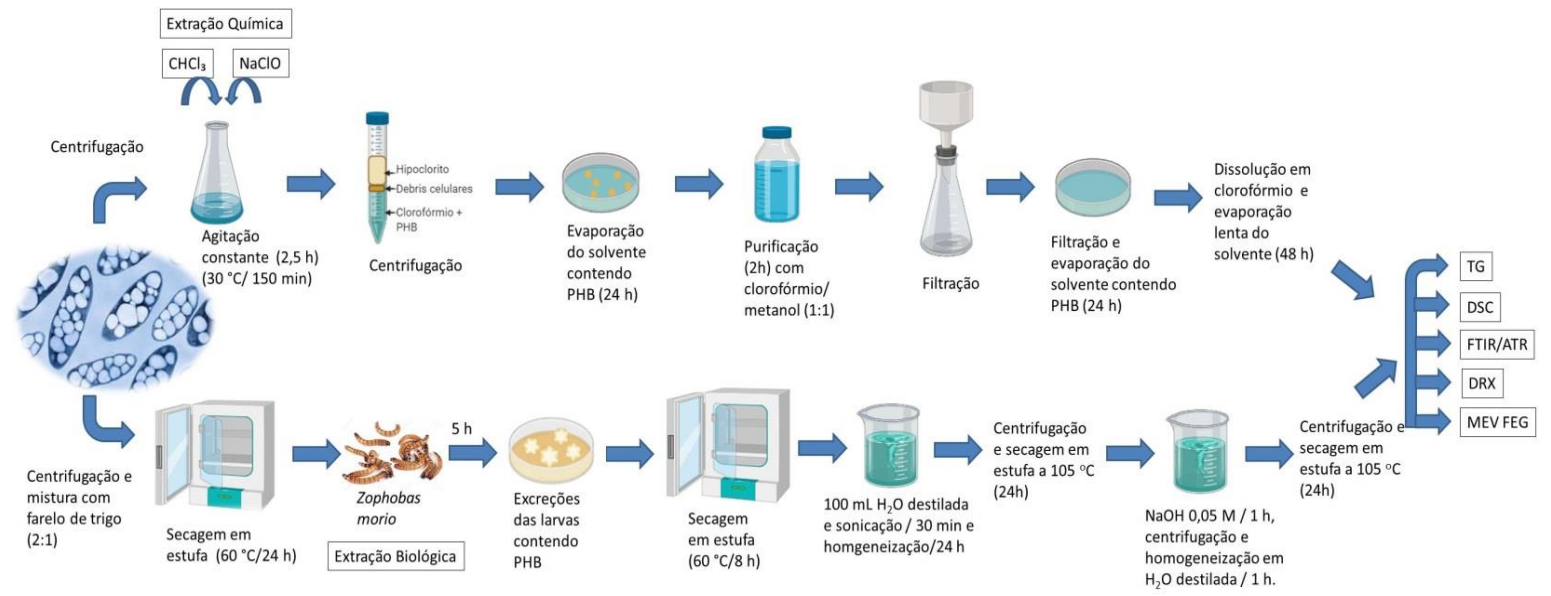

Figura 1: Fluxograma experimental demonstrando as etapas dos processos de extração pelos métodos químico e biológico.

\subsection{Biossíntese do PHB}

O micro-organismo utilizado neste trabalho foi a bactéria Cupriavidus necator - DSM 545. Para a ativação das células foi utilizado um frasco de Erlenmeyer aletado contendo $100 \mathrm{~mL}$ de caldo nutriente (NB) composto por 5,0 g. $\mathrm{L}^{-1}$ de peptona de carne e 3,0 g.L $\mathrm{L}^{-1}$ de extrato de carne. As células de Cupriavidus necator, mantidas em placa de Petri sob refrigeração, foram transferidas para o frasco. Posteriormente, o frasco foi incubado em um agitador (B. Braun CERTOMAT HK) em movimento rotatório de $150 \mathrm{rpm}$ a $30{ }^{\circ} \mathrm{C}$, overnight $( \pm 18 \mathrm{~h})$.

Para a produção de PHB foi o Meio Mineral (MM), descrito por Ramsay et al., (1990) com alterações propostas por ARAGÃO [25]. Resumidamente, o meio foi composto: glicose $\left(15 \mathrm{~g} \cdot \mathrm{L}^{-1}\right)$, frutose $\left(15 \mathrm{~g} \cdot \mathrm{L}^{-1}\right)$, ácido nitriloacético $\left(0,19 \mathrm{~g} \cdot \mathrm{L}^{-1}\right)$, citrato férrico de amônia $\left(0,06 \mathrm{~g} \cdot \mathrm{L}^{-1}\right), \mathrm{MgSO}_{4} \cdot 7 \mathrm{H}_{2} \mathrm{O}\left(0,5 \mathrm{~g} \cdot \mathrm{L}^{-1}\right), \mathrm{CaCl}_{2}$. $2 \mathrm{H}_{2} \mathrm{O}\left(0,01 \mathrm{~g} \cdot \mathrm{L}^{-1}\right), \mathrm{NH}_{4} \mathrm{SO}_{4}\left(5 \mathrm{~g} \cdot \mathrm{L}^{-1}\right), \mathrm{Na}_{2} \mathrm{HPO}_{4} \cdot 12 \mathrm{H}_{2} \mathrm{O}\left(8,95 \mathrm{~g} \cdot \mathrm{L}^{-1}\right), \mathrm{KH}_{2} \mathrm{PO}_{4}(1,5 \mathrm{~g} \cdot \mathrm{L}-1) \mathrm{e}$ oligoelementos $\left(1 \mathrm{~mL} \cdot \mathrm{L}^{-1}\right)$. A solução de oligoelementos foi composta: $\mathrm{H}_{3} \mathrm{BO}_{3}\left(0,3 \mathrm{~g} \cdot \mathrm{L}^{-1}\right), \mathrm{CoCl}_{2} \cdot 6 \mathrm{H}_{2} \mathrm{O}$ $\left(0,2 \mathrm{~g} \cdot \mathrm{L}^{-1}\right), \mathrm{ZnSO}_{4} \cdot 7 \mathrm{H}_{2} \mathrm{O}\left(0,1 \mathrm{~g} \cdot \mathrm{L}^{-1}\right), \mathrm{MnCl}_{4} \cdot 4 \mathrm{H}_{2} \mathrm{O}\left(0,03 \mathrm{~g} \cdot \mathrm{L}^{-1}\right), \mathrm{Na}_{2} \mathrm{MoO}_{4} \cdot 2 \mathrm{H}_{2} \mathrm{O}\left(0,03 \mathrm{~g} \cdot \mathrm{L}^{-1}\right), \mathrm{NiCl}_{2}$. $6 \mathrm{H}_{2} \mathrm{O}\left(0,02 \mathrm{~g} \cdot \mathrm{L}^{-1}\right), \mathrm{CuSO}_{4} \cdot 5 \mathrm{H}_{2} \mathrm{O}\left(0,01 \mathrm{~g} \cdot \mathrm{L}^{-1}\right)$. 
Este processo foi dividido em duas etapas, uma etapa denominada pré-inoculo, conduzida de forma a estimular o crescimento das células sem nenhuma limitação de nutrientes, enquanto a segunda etapa, denominada cultivo, foi conduzida, com limitação da fonte de nitrogênio $\left(\mathrm{NH}_{4} \mathrm{SO}_{4}\left(2,3 \mathrm{~g} \cdot \mathrm{L}^{-1}\right)\right)$, mantendo-se os demais nutrientes e concentrações, para estimular a produção do polímero.

As células foram transferidas a uma taxa de $10 \%$ (V / V) e novamente incubadas em um agitador orbital a $150 \mathrm{rpm}, 30^{\circ} \mathrm{C}$ por $24 \mathrm{~h}$. Ao final do cultivo o meio contendo as células foi congelado para a posterior extração.

\subsection{Extração do PHB \\ 2.2.1 Extração química}

Para efeito de comparação utilizou-se também o método de extração de HAHN et al. [26], o qual utiliza uma dispersão de hipoclorito de sódio e clorofórmio. O meio de cultivo foi centrifugado a $6.000 \mathrm{rpm}$. As células foram ressuspensas em uma dispersão contendo $100 \mathrm{~mL}$ de hipoclorito de sódio e $100 \mathrm{~mL}$ de clorofórmio $(30 \% \mathrm{~m} / \mathrm{V})$. Esta suspensão foi agitada durante $150 \mathrm{~min}$ a $30{ }^{\circ} \mathrm{C}$. Após este tratamento uma nova etapa de centrifugação foi realizada na qual são obtidas três fases: a fase superior é composta pelo hipoclorito de sódio, na fase intermediaria ficam os debris celulares (também chamados de NPCM, ou materiais celulares não-PHB) e no fundo a solução de clorofórmio e $\mathrm{P}(3 \mathrm{HB})$. Removendo-se as fases superior e intermediaria e, vertendo-se a última fase em uma placa de Petri, posteriormente submetida a evaporação (24 h) obtém-se uma massa polimérica

Para a purificação do polímero, foi utilizada a metodologia proposta por GARCIA [27], assim, o polímero foi solubilizado em clorofórmio sob agitação constante a $60{ }^{\circ} \mathrm{C}$. Em seguida, adicionou-se n-hexano na proporção 1:1 (V/V), como agente não-solvente, promovendo a precipitação do PHB e, então, foi realizada a filtração a vácuo dos cristais poliméricos formados. Após o processo de filtração, os cristais foram vertidos em uma placa de Petri para a evaporação do solvente $(24 \mathrm{~h})$.

Os filmes poliméricos foram preparados após o processo de evaporação do solvente. Os biopolímeros foram solubilizados utilizando-se clorofórmio $(1 \% \mathrm{~m} / \mathrm{V}$ ) com agitação por $2 \mathrm{~h}$ em shaker (B. Braun CERTOMAT HK) em movimento rotatório a $150 \mathrm{rpm}$. Em seguida, as amostras foram vertidas em placas de Petri e alocadas em uma cuba de vidro saturada em clorofórmio. Os filmes poliméricos foram removidos após o período de evaporação completa do solvente ( $48 \mathrm{~h}$ ) e então secos em estufa $40{ }^{\circ} \mathrm{C}$ por $24 \mathrm{~h}$, levando ao todo um tempo de cerca de $126 \mathrm{~h}$ de processo. Os filmes obtidos foram encaminhados para posterior caracterização.

\subsubsection{Extração biológica}

Adaptando a metodologia de MURUGAN et al. [1] e ONG et al. [21], o meio de cultivo foi centrifugado (SP Labor) durante $10 \mathrm{~min}$ a $6.000 \mathrm{rpm}$, para separação das células de $C$. necator contendo PHB. A alimentação das larvas do Zophobas morio (50 g) foi realizada, durante um período de 16 dias, com uma mistura de farelo de trigo com a biomassa centrifugada numa razão de 2:1 (m/m), sendo a mistura seca em estufa (Quimis) a $60{ }^{\circ} \mathrm{C}$ por $24 \mathrm{~h}$. As larvas foram mantidas em recipientes plásticos em condições ambientais. De acordo com MURUGAN et al. [1], a quantidade de alimento necessário para as larvas deve corresponder a 5\% da massa corporal por dia das mesmas. Posteriormente, as fezes obtidas das larvas foram secas por $8 \mathrm{~h}$ em uma estufa (Quimis) a $60{ }^{\circ} \mathrm{C}$.

As fezes secas foram adicionadas em $100 \mathrm{~mL}$ de água destilada e submetidas a sonicação por $30 \mathrm{~min}$ utilizando-se $40 \mathrm{kHz}$ em um banho ultrassônico (Thornton) a temperatura ambiente [21]. Posteriormente, a mistura foi agitada por $24 \mathrm{~h}$ e centrifugada (SP Labor) a $6.000 \mathrm{rpm}$ por $5 \mathrm{~min}$ a $4{ }^{\circ} \mathrm{C}$.

O PHB recuperado foi seco em estufa (Quimis) a $105^{\circ} \mathrm{C}$ até atingir massa constante (cerca de $24 \mathrm{~h}$ ). O processo anterior foi repetido e o PHB recuperado foi agitado constantemente por $1 \mathrm{~h}$ com hidróxido de sódio 0,05 M. Após, a mistura foi centrifugada (SP Labor) a $6.000 \mathrm{rpm}$ por $5 \mathrm{~min} \mathrm{a} 4{ }^{\circ} \mathrm{C}$. O PHB recuperado passou pelo processo de agitação com água por $1 \mathrm{~h}$ e, novamente, centrifugou-se nas mesmas condições anteriores e então foi seco a $105^{\circ} \mathrm{C}$ até atingir massa constante (cerca de $24 \mathrm{~h}$ ), levando ao todo um tempo de cerca de $111 \mathrm{~h}$ de processo. Esse material foi utilizado para caracterizar a amostra. 


\subsection{Identificação das amostras}

As amostras obtidas pelos diferentes processos de extração foram identificadas conforme apresentado no Quadro 1.

Quadro 1: Identificação das amostras.

\begin{tabular}{cc}
\hline Amostra & Procedimento \\
\hline PHB_EQ & PHB extraído pelo método químico \\
\hline PHB_EB & PHB extraído pelo método biológico \\
\hline
\end{tabular}

\subsection{Caracterização das amostras de PHB obtidas pelos diferentes método de extração}

\subsubsection{Espectroscopia na região do infravermelho com transformada de Fourier com Acessório de Reflexão Total Atenuada (FTIR/ATR)}

Os espectros das amostras foram obtidos em um equipamento da marca Perkin Elmer modelo 65 FTIR, no intervalo de 4.000 a $600 \mathrm{~cm}^{-1}$, com 32 varreduras e resolução de $4 \mathrm{~cm}^{-1}$.

\subsubsection{Difratometria de raios-X (DRX)}

A difração de raios $X$ foi medida com um difratômetro de raios X (Modelo XRD 6000, Shimadzu). Os difratogramas foram registrados usando radiação $\mathrm{CuK \alpha}$ com ângulo $2 \theta$ variando de 5 a $70^{\circ}$, velocidade de varredura de $1^{\circ} /$ min e $40 \mathrm{kV}$. O software X'Pert HighScore Plus foi utilizado para analisar os difratogramas e determinar o grau de cristalinidade $\left(\alpha_{C}\right)$ das membranas. $O \alpha_{C}$ foi determinado em função das áreas correspondentes aos picos cristalinos e ao halo amorfo (pico estendido sob os picos cristalinos) 28 pela equação 1:

$$
\alpha_{c}=\frac{A_{c}}{A_{c}+A_{a}} * 100
$$

\subsubsection{Termogravimetria (TG)}

Esta análise foi realizada com o objetivo de analisar a estabilidade térmica e pureza das amostras após os processos de extração. Em torno de 3,5 mg de amostra foram inseridos em cadinhos de platina e as análises foram conduzidas em equipamento da marca Shimadzu modelo TGA-50, com aquecimento de 25 a $900{ }^{\circ} \mathrm{C}$ a uma taxa de $10^{\circ} \mathrm{C} / \mathrm{min}$ em atmosfera inerte, com fluxo de $\mathrm{N} 2$ de $50 \mathrm{~mL} / \mathrm{min}$.

\subsubsection{Calorimetria exploratória diferencial (DSC)}

Foi utilizada com o objetivo de determinar a temperatura de fusão $\left(\mathrm{T}_{\mathrm{m}}\right)$, entalpia de fusão $\left(\Delta \mathrm{H}_{\mathrm{m}}\right)$, grau de cristalinidade $\left(\alpha_{C}\right)$, entalpia de cristalinidade $\left(\Delta \mathrm{H}_{\mathrm{C}}\right)$ e temperatura de transição vítrea $\left(\mathrm{T}_{\mathrm{g}}\right)$. Em torno de 3,5 $\mathrm{mg}$ de amostra foram dispostas em cadinhos de alumínio hermeticamente fechados e as análises foram conduzidas em equipamento da marca TA Instruments modelo Q20, com taxa de aquecimento de $10{ }^{\circ} \mathrm{C} / \mathrm{min}$ em atmosfera inerte, com fluxo de $\mathrm{N}_{2}$ de $50 \mathrm{~mL} / \mathrm{min}$, com faixa de temperatura de 25 a $200{ }^{\circ} \mathrm{C}$, resfriamento rápido de 200 até $-70{ }^{\circ} \mathrm{C}$ do tipo jumping e $2^{\circ}$ aquecimento até $200{ }^{\circ} \mathrm{C}$ a $10{ }^{\circ} \mathrm{C} / \mathrm{min}$. A $\mathrm{T}_{\mathrm{m} 1}$ foi determinada a partir das curvas do $1^{\circ}$ aquecimento, enquanto a $\mathrm{T}_{\mathrm{g} 2}$ foi detectada no $2^{\circ}$ aquecimento. $\mathrm{O} \alpha_{\mathrm{C} 1}$ do material foi calculado por meio da razão entre o $\Delta \mathrm{H}_{\mathrm{m} 1}$ da amostra e a entalpia de fusão do polímero supondo $100 \%$ cristalino $\left(\Delta \mathrm{H}_{\mathrm{m}}{ }^{0}\right)$, de $142 \mathrm{~J} / \mathrm{g}$ [29], conforme observado na equação 2:

$$
\alpha_{c}=\left[100 * \frac{\Delta H_{m}-\Delta H_{c}}{\Delta H_{m^{0}}}\right]
$$

\subsubsection{Microscopia Eletrônica de Varredura (MEV-FEG)}

A análise foi efetuada em um equipamento MEV XL30 FEG, para avaliar a morfologia da superfície do polímero. As amostras foram fixadas em um suporte metálico e recobertas com uma fina camada de ouro para torná-las condutoras, utilizando-se um metalalizador de amostras. 


\section{RESULTADOS E DISCUSSÕES}

\subsection{Espectroscopia na região do infravermelho com transformada de Fourier com Acessório de Reflexão Total Atenuada (FTIR/ATR)}

Na Figura 2 são apresentados os espectros obtidos por FTIR/ATR referente às amostras de PHB extraídas pelo método químico e biológico. Verificou-se no espectro obtido para as amostras (Figura 2) bandas em 2977 e $2935 \mathrm{~cm}^{-1}$ (PHB_EQ) e 2976 e $2933 \mathrm{~cm}^{-1}$ (PHB_EB) relacionadas ao grupo assimétrico metil $\left(\mathrm{CH}_{3}\right)$ e ao grupo simétrico metileno $\left(\mathrm{CH}_{2}\right)$, respectivamente, correspondentes às cadeias laterais do monômero do PHB, o que está de acordo com a literatura [30].

Observou-se uma banda de absorção em $1720 \mathrm{~cm}^{-1}$ (Figura 2) correspondente à carbonila $(\mathrm{C}=\mathrm{O})$ associada aos agrupamentos cristalinos, valor idêntico ao descrito por BHUWAL et al. [31] referente a esta ligação.

De acordo com TÃNASE et al. [32], a presença de uma banda em $1379 \mathrm{~cm}^{-1}$ é atribuída ao alongamento simétrico do grupo metil $\left(\mathrm{CH}_{3}\right)$, banda também observada no espectro, Figura 2, obtido da amostra PHB_EQ e também, muito próxima à observada no espectro da amostra PHB_EB em $1380 \mathrm{~cm}^{-1}$.

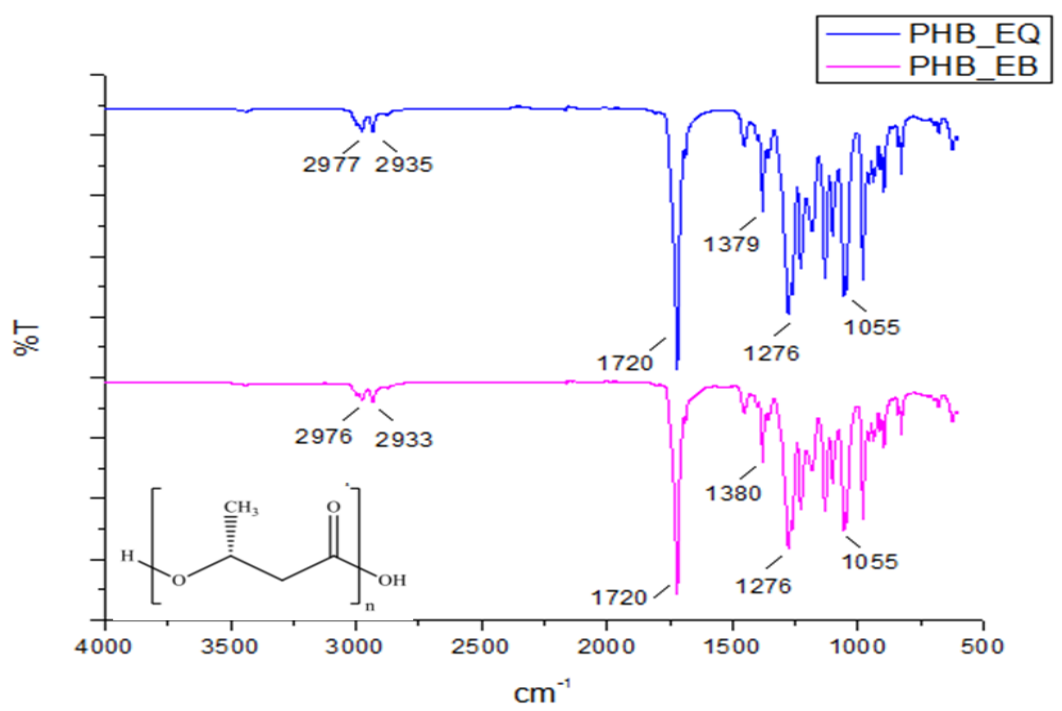

Figura 2: Espectros obtidos por FTIR/ATR das amostras de PHB_EQ e PHB_EB.

Na Figura 2 foi possível observar a presença de bandas em 1276 e $1055 \mathrm{~cm}^{-1}$ e, segundo LÓPEZCUELLAR et al. [30], bandas de absorção entre 1300 e $1000 \mathrm{~cm}^{-1}$ são relacionados a vibrações de alongamento C-O-C. Em um estudo realizado por BHUWAL et al. [31], também foi observada banda em $1273 \mathrm{~cm}^{-1}$ e foi atribuída a esse estiramento, valor semelhante ao encontrado no presente trabalho para ambas as amostras, de $1276 \mathrm{~cm}^{-1}$. Portanto, as bandas observadas no espectro correspondem às ligações químicas dos grupamentos presentes no polímero, garantindo que o PHB foi de fato sintetizado e extraído por ambos dos métodos.

Na Tabela 1 são apresentadas as bandas observadas no espectro de infravermelho para as amostras PHB_EQ e PHB_EB. 
Tabela 1: Bandas características no espectro para PHB_EQ e PHB_EB.

\begin{tabular}{c|c|c|c}
\hline Componente & PHB_EQ & PHB_EB & Literatura \\
\hline Grupo assimétrico metil $\left(\mathrm{CH}_{3}\right)$ & $2977 \mathrm{~cm}^{-1}$ & $2976 \mathrm{~cm}^{-1}$ & $2978 \mathrm{~cm}^{-1}[30]$ \\
\hline Grupo simétrico metileno $\left(\mathrm{CH}_{2}\right)$ & $2935 \mathrm{~cm}^{-1}$ & $2933 \mathrm{~cm}^{-1}$ & $2935 \mathrm{~cm}^{-1}[30]$ \\
\hline Carbonila $(\mathrm{C}=\mathrm{O})$ & $1720 \mathrm{~cm}^{-1}$ & $1720 \mathrm{~cm}^{-1}$ & $1720 \mathrm{~cm}^{-1}[31]$ \\
\hline $\begin{array}{c}\text { Alongamento simétrico do metil } \\
\left(\mathrm{CH}_{3}\right)\end{array}$ & $1379 \mathrm{~cm}^{-1}$ & $1380 \mathrm{~cm}^{-1}$ & $1379 \mathrm{~cm}^{-1}[32]$ \\
\hline Alongamento C-O-C & $1276 \mathrm{e} 1055 \mathrm{~cm}^{-1}$ & $1276 \mathrm{e} 1055 \mathrm{~cm}^{-1}$ & $1273 \mathrm{~cm}^{-1}[31]$ \\
\hline
\end{tabular}

\subsection{Difratometria de raios-X (DRX)}

$\mathrm{Na}$ Figura 3 são apresentados os difratogramas de raios-X para as amostras extraídas pelo método químico e biológico.

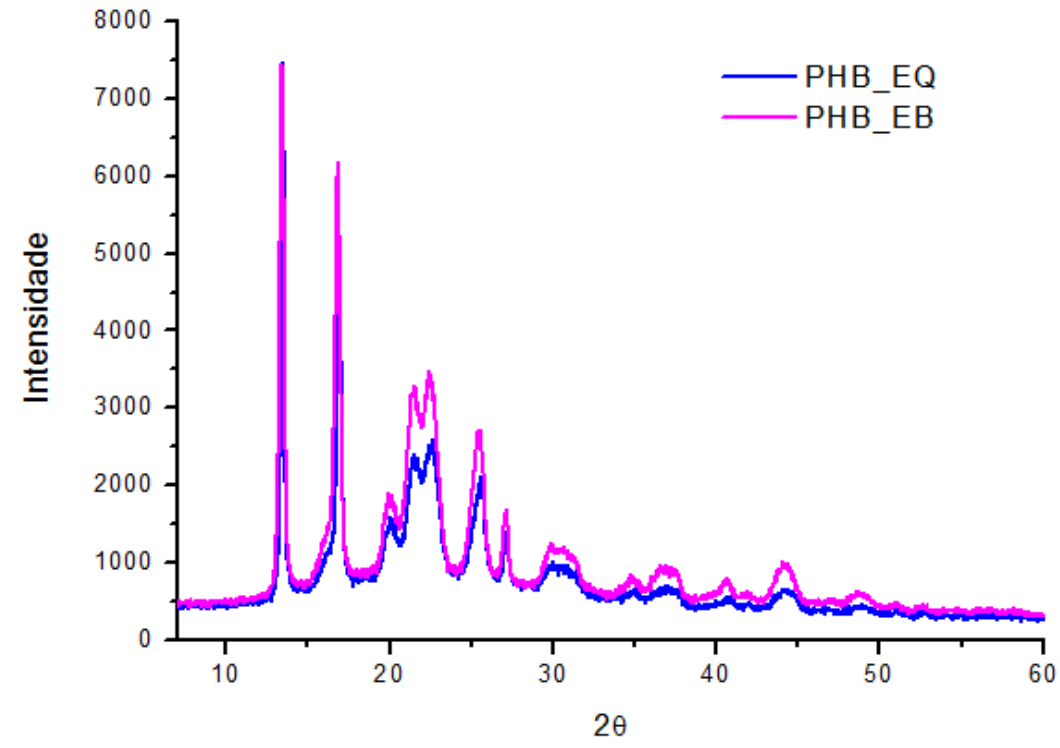

Figura 3: Perfis de difração de raios-X para PHB_EQ e PHB_EB.

Conforme observado na Figura 3, não houve deslocamento dos picos de difração das amostras PHB_EQ e PHB_EB, apresentando picos de difração em $2 \theta$ bem definidos, correspondentes às reflexões (020) e (110), em $13,5^{\circ}$ para PHB_EQ e $13,3^{\circ}$ para PHB_EB e $16,9^{\circ} \mathrm{em}$ ambas as amostras, respectivamente, valores similares ao descrito por GARCIA [27]. Observou-se também, para PHB_EQ e PHB_EB, reflexões em 19,9 $9^{\circ}$ e, segundo WANG et al. [33], esse pico de refração é atribuido à forma $\beta$ dos cristais do polímero. Outras

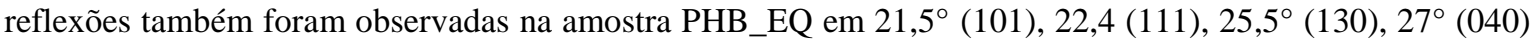
e na amostra PHB_EB picos de difração em 21,6 (101) $22,5^{\circ}$ (111), 25,5 $5^{\circ}$ (130) e $27^{\circ}$ (040), conforme relatado também na literatura $[27,33]$.

Dos difratogramas de raios-X, Figura 3, determinou-se o grau de cristalinidade do PHB_EQ e PHB_EB, sendo, 56,7 e 58,4\%, respectivamente, valores similares ao descrito por GARCIA [27], pelo mesmo método, para o PHB, de 61,66\% e inferior ao cálculado por meio da entalpia de fusão obtida por DSC, de 63 e $64 \%$. Porém, os valores obtidos ainda encontram-se dentro da faixa de cristalinidade, de 55 a $80 \%$ [34].

\subsection{Termogravimetria (TG)}

$\mathrm{Na}$ Tabela 2 são apresentados os dados obtidos a partir das curvas termogravimétricas (curvas TG) obtidas para as amostras de PHB extraída pelo método químico (PHB_EQ) e biológico (PHB_EB).

Observa-se que o perfil de degradação térmica ocorreu em um único estágio para ambas as amostras, o que também foi observado no estudo realizado por GARCIA [27]. Os filmes poliméricos extraídos pelos 
métodos químico e biológico apresentaram temperaturas de início de degradação $\left(\mathrm{T}_{\text {onset }}\right)$ de 285 e $290{ }^{\circ} \mathrm{C}$, respectivamente, valores ligeiramente superiores ao encontrado por GARCIA [27], de $282{ }^{\circ} \mathrm{C}$. MURUGAN et al. [1] também compararam a extração de $\mathrm{P}(3 \mathrm{HB}-c o-3 \mathrm{HHx})$ usando clorofórmio com um método biológico usando Tenebrio molitor e também observaram um incremento na estabilidade térmica de $5{ }^{\circ} \mathrm{C}$ na amostra extraída pelo método biológico.

Conforme descrito por GARCIA [27], a análise de TG pode ser utilizada como indicativo do grau de pureza do polímero, representado pela perda de massa. Logo, as porcentagens de perda de massa obtidas para PHB_EQ e PHB_EB foram de 98,4 e 98,7\%, respectivamente, valores semelhantes ao descrito por HAHN et al. [35], de $98 \%$ para o PHB. As impurezas presentes no biopolímero podem ser resultado da ligação de hidrogênio do mesmo com proteínas e cátions do meio de cultivo [35].

Tabela 2: Dados de $\mathrm{T}_{\text {onset, }}$ perda de massa e teor de resíduos obtidos a partir das curvas termogravimétricas (curvas TG) para as amostras PHB_EQ e PHB_EB.

\begin{tabular}{c|c|c|c}
\hline & $\mathbf{T}_{\text {onset }}\left({ }^{\circ} \mathbf{C}\right)$ & Perda de massa (\%) & Resíduo (\%) \\
\hline PHB_EQ & 285 & 98,4 & 1,6 \\
\hline PHB_EB & 290 & 98,7 & 1,3 \\
\hline
\end{tabular}

\subsection{Calorimetria exploratória diferencial (DSC)}

Na Figura 4 são apresentadas as curvas de DSC das amostras de polímeros extraídos pelos métodos químico e biológico. A $\mathrm{T}_{\mathrm{m} 1}$ e o $\alpha_{\mathrm{C} 1}$ foram determinados a partir do $1^{\circ}$ aquecimento (Figura 4a) considerando a característica térmica intrínseca das amostras, enquanto a $\mathrm{T}_{\mathrm{g} 2}$ foi obtida a partir das curvas do $2^{\circ}$ aquecimento (Figura 4c). Considerando que o PHB possui alto grau de cristalinidade, sua $\mathrm{T}_{\mathrm{g}}$ geralmente não é muito nítida, pois a $\mathrm{T}_{\mathrm{g}}$ está relacionada com a parte amorfa das cadeias poliméricas. Outro fator, é que a $\mathrm{T}_{\mathrm{g}}$ do $\mathrm{PHB}$ se situa entre -5 e $5^{\circ} \mathrm{C}$ [36] não sendo possível detectá-la no $1^{\circ}$ aquecimento, pois o ensaio se iniciou a partir da temperatura ambiente. Além disso, na primeira corrida há a história térmica do corpo de prova. Desta forma, com o objetivo de detectar os dados de $\mathrm{T}_{\mathrm{g} 2}, \Delta \mathrm{H}_{\mathrm{m} 2}$, e $\alpha_{\mathrm{C} 2}$ um $2^{\circ}$ aquecimento foi realizado com as amostras, após a técnica de resfriamento rápido tipo jumping (Figura 4b), o que pode ter tornado a amostra menos cristalina.

Verificou-se que as $\mathrm{T}_{\mathrm{m} 1 \text { 's }}$ do PHB extraído pelos métodos químico e biológico (Figura 4a), foram de 174 e $172{ }^{\circ} \mathrm{C}$, respectivamente, valores semelhantes ao descrito por HAHN et al. [35] (173 $\left.{ }^{\circ} \mathrm{C}\right)$ e por MACHADO et al. [34] $\left(176^{\circ} \mathrm{C}\right)$. As entalpias de fusão determinadas foram de 89,6 J/g para PHB_EQ e 90,9 $\mathrm{J} / \mathrm{g}$ para PHB_EB, valores semelhantes ao reportado na literatura por MACHADO et al., [34], de $93 \mathrm{~J} / \mathrm{g}$.

Considerando o $1^{\circ}$ aquecimento, os graus de cristalinidade das amostras PHB_EQ e PHB_EB, foram de 63 e $64 \%$, respectivamente, valores dentro da faixa de cristalinidade para o PHB, que se situa entre 55 e $80 \%$, conforme descrito por MACHADO et al. [34]. Verifica-se que os valores de $\alpha_{\mathrm{Cl}}$ do $1^{\mathrm{o}}$ aquecimento por DSC mostram o mesmo comportamento que os determinados por DRX, que é considerada uma técnica mais confiável para a determinação da cristalinidade. Já no $2^{\circ}$ aquecimento (Figura 4c), os valores foram menores, visto que houve uma alteração na organização das cadeias. Isto pode ter ocorrido em decorrência do resfriamento jumping. Nesse processo, houve um resfriamento rápido de modo a não haver tempo para que a cristalização ocorra plenamente. Nestas condições, há a formação de um grande número de núcleos cristalinos na amostra, porém a propagação do crescimento dos cristais não foi significativa [37]. Assim, os valores de $\alpha_{\mathrm{C} 2}$ do $2^{\circ}$ aquecimento foram 54 e $40 \%$, para PHB_EQ e PHB_EB, respectivamente.

Nas curvas de resfriamento mostradas na Figura $4 \mathrm{~b}$ observou-se um pico de cristalização mais intenso para a amostra PHB_EQ $\left(\Delta \mathrm{H}_{\mathrm{CR}} 44,7 \mathrm{~J} / \mathrm{g}\right)$ quando comparado ao PHB_EB $\left(\Delta \mathrm{H}_{\mathrm{CR}} 19,5 \mathrm{~J} / \mathrm{g}\right)$. Desta forma, conclui-se que o resfriamento jumping alterou de forma mais pronunciada a cristalinidade da amostra extraída pelo método biológico $(40 \%)$ do que pelo método químico (54\%), explicando o fato da $\mathrm{T}_{\mathrm{g} 2}$ do PHB_EB ter se apresentado mais nítida, pois essa amostra apresenta um maior conteúdo de fase amorfa, o que pode ser justificado pelo fato da amostra biológica possuir uma menor variação dos tamanhos das cadeias. Uma das evidências desse fato é que durante o $1^{\circ}$ aquecimento a amostra PHB_EQ apresentou um pico com um ombro, enquanto a amostra PHB_EB apresentou um pico de fusão único. A extração biológica acaba envolvendo aspectos enzimáticos que apresentam maior seletividade fazendo com que haja uma uniformidade do tamanho das cadeias. Não foi possível determinar o $\Delta H_{m R}$ no resfriamento e consequentemente o $\alpha_{\mathrm{CR}}$, devido ao fato da linha base não ter se estabilizado durante a fusão no resfriamento. 
Por meio das curvas do $2^{\circ}$ aquecimento (Figura $4 \mathrm{c}$ ), observou-se que as $\mathrm{T}_{\mathrm{g}}$, para ambas as amostras PHB_EQ e PHB_EB que foram de $-3,3$ e $-4,4{ }^{\circ} \mathrm{C}$, respectivamente. Esses valores foram semelhantes ao encontrado por MOUSAVIOUN et al. [38]. Ainda no $2^{\circ}$ aquecimento, a amostra extraída pelo método biológico apresentou uma $\mathrm{T}_{\mathrm{g} 2}$ mais nítida quando comparada com a amostra extraída pelo método químico, conforme já explicado. Além disso, nota-se que houve a formação de um pico de cristalização bem maior na amostra PHB_EB e, ainda, que a fusão do material ocorreu em um único pico, indicando uma maior homogeneidade no tamanho dos cristais, características observadas também em uma análise de DSC realizado por WELLEN et al. [39].
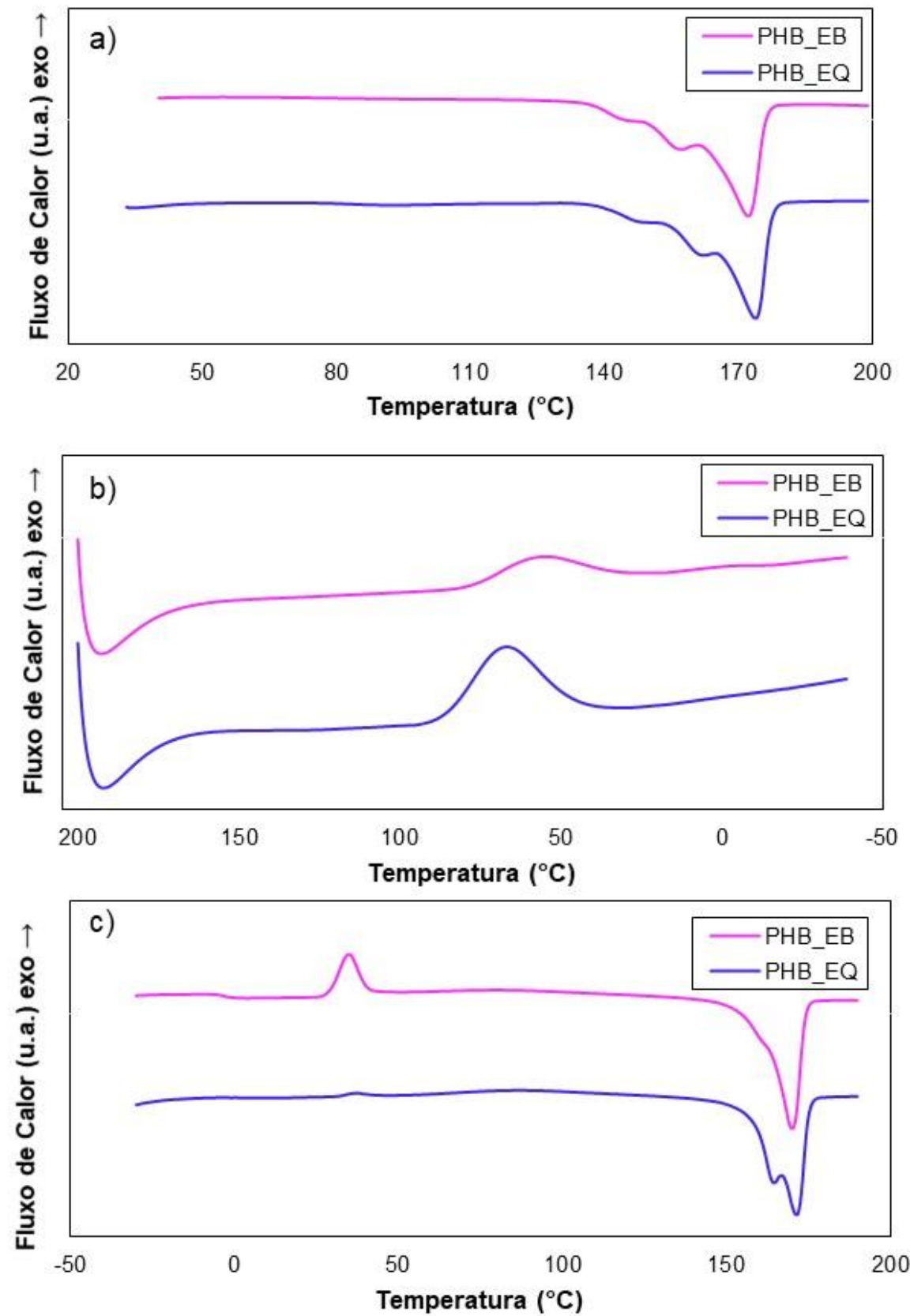

Figura 4: Curvas obtidas por DSC das amostras extraídas pelo método químico e biológico: a) $1^{\circ}$ aquecimento; b) resfriamento tipo jumping e c) $2^{\circ}$ aquecimento. 
Na Tabela 3, são apresentados os resultados obtidos a partir do aquecimento das curvas de DSC.

Tabela 3: Dados de temperatura de fusão $\left(T_{m}\right)$, entalpia de fusão $\left(\Delta \mathrm{H}_{\mathrm{m}}\right)$, grau de cristalinidade $\left(\alpha_{\mathrm{C}}\right)$ e temperatura de transição vítrea $\left(\mathrm{T}_{\mathrm{g}}\right)$ para PHB_EQ e PHB_EB.

\begin{tabular}{c|c|c|c|c|c|c|c|c|c|c}
\hline & $\begin{array}{c}\mathbf{T}_{\mathbf{m} 1} \\
\left({ }^{\circ} \mathbf{C}\right)\end{array}$ & $\begin{array}{c}\Delta \mathbf{H}_{\mathbf{m} 1} \\
(\mathbf{J} / \mathbf{g})\end{array}$ & $\begin{array}{c}\boldsymbol{\alpha}_{\mathbf{C} 1} \\
(\boldsymbol{\%})\end{array}$ & $\begin{array}{c}\Delta \mathbf{H}_{\mathbf{c R}} \\
(\mathbf{J} / \mathbf{g})\end{array}$ & $\begin{array}{c}\Delta \mathbf{H}_{\mathbf{m R}} \\
(\mathbf{J} / \mathbf{g})\end{array}$ & $\begin{array}{c}\boldsymbol{\alpha}_{\mathbf{C R}} \\
(\boldsymbol{\%})\end{array}$ & $\begin{array}{c}\Delta \mathbf{H}_{\mathbf{c} 2} \\
(\mathbf{J} / \mathbf{g})\end{array}$ & $\begin{array}{c}\Delta \mathbf{H}_{\mathbf{m} 2} \\
(\mathbf{J} / \mathbf{g})\end{array}$ & $\begin{array}{c}\boldsymbol{\alpha}_{\mathbf{C 2}} \\
(\boldsymbol{\%})\end{array}$ & $\begin{array}{c}\mathbf{T}_{\mathbf{g} 2} \\
\left({ }^{\circ} \mathbf{C}\right)\end{array}$ \\
\hline PHB_EQ & 174 & 89,6 & 63 & 44,7 & nd & nd & 1,2 & 78,4 & 54 & $-3,3$ \\
\hline PHB_EB & 172 & 90,9 & 64 & 19,5 & nd & nd & 15,8 & 72,2 & 40 & $-4,4$ \\
\hline
\end{tabular}

* Os índices $1, \mathrm{R}$ e 2 referem-se ao $1^{\circ}$ aquecimento, resfriamento e $2^{\circ}$ aquecimento, respectivamente. nd = não determinado

\subsection{Microscopia Eletrônica de Varredura (MEV-FEG)}

Na Figura 5 estão apresentadas as micrografias de MEV-FEG da superfície das amostras PHB_EQ e PHB_EB. Observou-se uma similaridade entre as morfologias, ambas as amostras apresentaram superfície porosa em quase toda a extensão. Logo, a extração biológica não ocasionou a formação de outras impurezas na superfície do polímero quando comparada com a amostra de referência (PHB_EQ), mostrando que a extração biológica, além de promover propriedades térmicas e estruturais semelhantes ao PHB extraído pelo método químico, proporciona também uma morfologia equivalente.
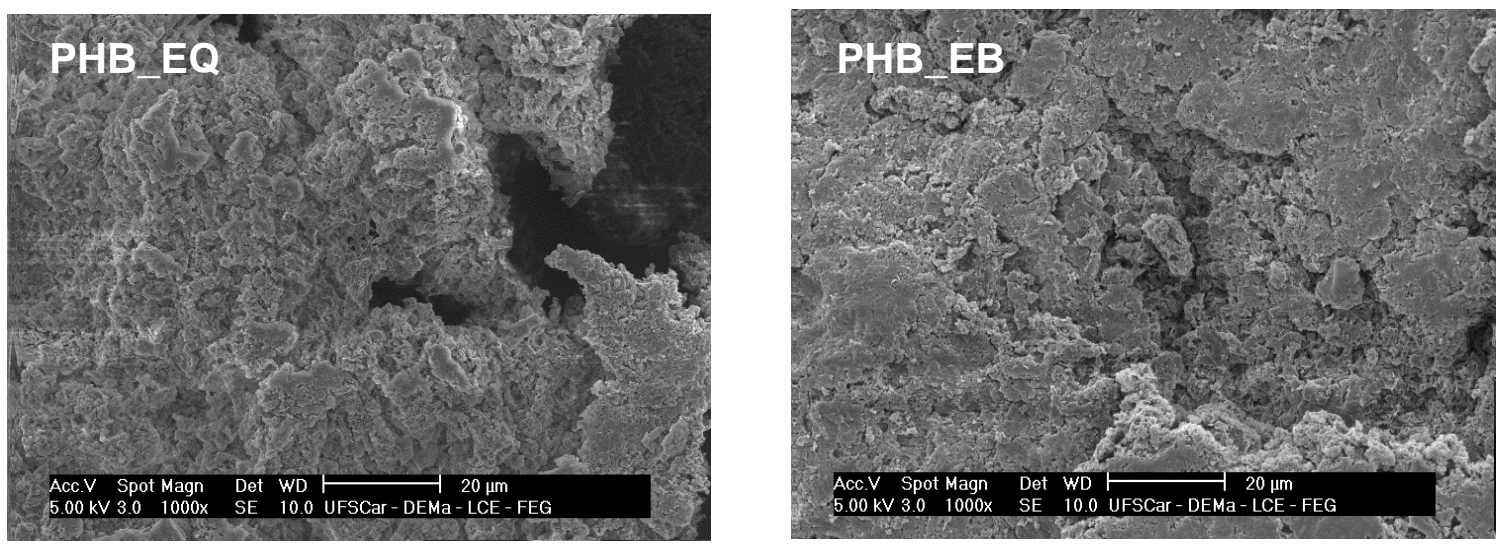

Figura 5: MEV da superfície das amostras PHB_EQ e PHB_EB.

\section{CONCLUSÃO}

Os diferentes métodos de extração possibilitaram a obtenção do polímero desejado, como evidenciado pelas análises de FTIR. A partir da análise de DRX, verificaram-se picos de difração característicos do PHB em ambas as amostras, o grau de cristalinidade apresentado foi de 56,7 para o PHB_EQ e 58,4\% para PHB_EB, demonstrando que esta propriedade foi pouco alterada pelo processo de extração biológico.

As análises de DSC, também apresentaram similaridade quanto à $\mathrm{T}_{\mathrm{m} 1}$ de 174 e $173{ }^{\circ} \mathrm{C}, \alpha_{\mathrm{C} 1}$ de 63 e $64 \%$ e $T_{\mathrm{g} 2}$ de $-3,3$ e $-4,4{ }^{\circ} \mathrm{C}$ e para as amostras PHB_EQ e PHB_EB, respectivamente. Bem como, a análise de TG, apontou uma pureza de 98,4 e $98,7 \%$ e $\mathrm{T}_{\text {onset }}$ de 285 e $290^{\circ} \mathrm{C}$ para os dois polímeros, demonstrando uma estabilidade térmica e pureza ligeiramente superior para a amostra extraída pelo método biológico

Sendo assim, a extração biológica por larvas de Zophobas morio foi eficiente para extrair o PHB, que apresentou propriedades ligeiramente superiores ao polímero extraído quimicamente, como maior estabilidade térmica e maior pureza, reduzindo a quantidade de solvente exigida no processo bem como o tempo de extração de $126 \mathrm{~h}$ para $111 \mathrm{~h}$, tornando o processo de extração mais ambientalmente amigável, sugerindo que o processo de extração química pode ser substituído pela metodologia de extração biológica.

\section{BIBLIOGRAFIA}

[1] MURUGAN, P., HANA, L., GANB, C.Y., et al., "A new biological recovery approach for PHA using mealworm, Tenebrio molitor”, Journal of Biotechnology, v. 239, pp. 98 - 105, 2016. 
[2] GLASER, J.A. "Polymer recycling using microbes". Clean Technologies and Environmental Policy, v 19(7), pp. 1817-1823, 2017.

[3] ALLEN, S., ALLEN, D., PHOENIX, V.R., et al., "Atmospheric transport and deposition of microplastics in a remote mountain catchment”. Nature Geoscience, v. 12, n. 5, pp. 339, 2019.

[4] MA, P., XU, P., CHEN, M., et al., "Structure-property relationships of reactively compatibilized PHB/EVA/starch blends", Carbohydrate Polymers, v. 108, pp. 299 - 306, 2014.

[5] NERY, T.B.R., SANTOS, Z.I.G., JOSE, N.M. "Desenvolvimento e caracterização de biocompósitos de polihidroxibutirato e fibra de bananeira", Matéria (Rio J.), Rio de Janeiro, v. 23, n. 4, e12257, 2018.

[6] DIETRICH, K., DUMONT, M.J., DEL RIO, L.F., et al., "Producing PHAs in the bioeconomy Towards a sustainable bioplastic". Sustainable Production and Consumption, v. 9, pp. 58 - 70, 2017.

[7] LAURENCE, W.M. Film Properties of Plastics and Elastomers. 3 ed. William Andrew, 2012.

[8] ZHENG, Z., OPHIR, O., GOYAL, R. KOHN, J. Handbook of Polymer Applications in Medicine and Medical Devices. 1 ed. William Andrew, 2014.

[9] RAVEENDRAN, S., NAGAPOOSAM, S., PARAMESWARAN, B., et al., "Pentose-rich hydrolysate from acid pretreated rice straw as a carbon source for the production of poly-3-hydroxybutyrate", Biochemical Engineering Journal, v. 78, pp. 67-72, 2013.

[10] WELLEN, R.M.R., RABELLO, M.S., FECHINE, G.J.M. et al., "The melting behaviour of poly (3hydroxybutyrate) by DSC", Polymer Testing, v. 32, pp. 215-220, 2013.

[11] SILVA, L.F., GOMEZ, J.G.C., ROCHA, R.C., et al., "Produção Biotecnológica de polihidroxialcanoatos para a Geração de Polímeros Biodegradáveis no Brasil', Química Nova, v. 30, n. 7, pp. 1732- 1743, 2007.

[12] APATI, G.P., KELBERT, M., SOMBRIO, B.R., et al., "Evaluation of the addition of glycerol to Cupriavidus necator culture medium over Poly (3-hydroxybutyrate) production", Matéria (Rio J.), Rio de Janeiro, v. 23, n. 1, e-11978, 2018.

[13] LI, Z., LOH, X. J., "Water soluble polyhydroxyalkanoates: future materials for therapeutic applications", Chemical Society Reviews, v. 44, n. 10, pp. 2865- 2879, 2015.

[14] MISRA, M., PANDEY, J., MOHANTY, A. "Biocomposites: Design and Mechanical Performance”. 1 ed. Woodhead Publishing: Cambridge, UK, 2015.

[15] MANAVITEHRANI, I., FATHI, A., BADR, H., et al., "Biomedical applications of biodegradable polyesters", Polymers, v. 8, n. 1, pp. 20- 52, 2016.

[16] OBRUCA, S., BENESOVA, P., OBORNA, J., et al., "Application of protease-hydrolyzed whey as a complex nitrogen source to increase poly (3-hydroxybutyrate) production from oils by Cupriavidus necator", Biotechnology Letters, v. 36, pp. 775- 781, 2014.

[17] ARAMVASH, A., SHAHABI, A.Z., AGHJEH, D.S., et al., "Statistical physical and nutrient optimization of bioplastic polyhydroxybutyrate production by Cupriavidus necator", International Journal of Environmental Science and Technology, v. 12, n. 7, pp. 2307- 2316, 2015.

[18] JACQUEL, N., LO, C., WEI, Y. et al., "Isolation and purification of bacterial poly(3hydroxyalkanoates)", Biochemical Engineering Journal, v. 39, pp. 15-27, 2008.

[19] FLANAGAN, R.J., POUNDER, D.J., "A chloroform-related death: Analytical and forensic aspects", Forensic Science International, v. 197, pp. 89-96, 2010.

[20] TELLES, R., SARAN, L.M., UNÊDA-TREVISOLLI, S. H., "Produção, propriedades e aplicações de bioplástico obtido a partir da cana-de-açúcar”, Ciência \& Tecnologia: FATEC-JB, v. 2, n. 1, pp. 52-63, 2011.

[21] ONG, S.Y., KHO, H.P., RIEDEL, S.L., et al., "An integrative study on biologically recovered polyhydroxyalkanoates (PHAs) and simultaneous assessment of gut microbiome in yellow mealworm", Journal of Biotechnology, v. 265, pp. 31-39, 2017.

[22] COSTA, S.M., "Proteínas de Larvas de Tenebrio molitor (L. 1758): Extração, Caracterização e Aplicação num Produto Alimentar”, Dissertação M.Sc. Universidade de Lisboa, Lisboa, Portugal, 2017.

[23] MORALES-RAMOS, J.A., ROJAS, M.G., KAY, S., et al., "Self-selection of two diet components by Tenebrio molitor (coleptera Tenebrionidae) larvae and its impact on fitness", Environmental Entomology, v. 40, n. 5, pp. 1285- 1294, 2011. 
[24] YANG, Y., YANG, J., WU, W.M., et al., "Biodegradation and mineralization of polystyrene by plasticeating mealworms: Part 1. Chemical and physical characterization and isotopic tests", Environmental Science Technology, v. 49, n. 20, pp. 12080-12086, 2015.

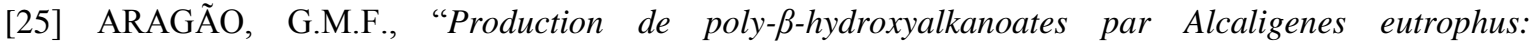
caractérisation cinétique et contribution à l'optimisation de la mise en oeuvre dês cultures". Toulouse. These du Doctorale (Sciences de la Vie), L'institut National des Sciences Appliquees de Toulose, 1996.

[26] HAHN, S.K., CHANG, Y.K., KIM, B.S., et al., "Optimization of microbial poly (3-hydroxybutyrate) recovery using dispersions of sodium hypoclorite solution and chloroform", Biotechnology and Bioengineering, v. 44, pp. 256-261, 1994.

[27] GARCIA, M.C.F., "Proposta de um processo de extração de poli(3-hidroxibutirato) produzido por Cupriavidus necator e seu efeito sobre as características do polímero", Dissertação M.Sc. Universidade Federal de Santa Catarina, Florianóplois, Brasil, 2006.

[28] FOSTER, E.J, MOON, R.J., AGARWAL, U.P., et al. "Current characterization methods for cellulose nanomaterials". Chemical Society Reviews. V. 47, n. 8, pp 2609-2679, 2018.

[29] TSUJI, H., IKADA, Y., "Blends of aliphatic polyesters. 1. Physical properties and morphologies of solution-cast blends from poly(DL-lactide) and poly(E-caprolactone)", Journal of Applied Polymer Science, v. 60, n. 1, pp. 2367-2375, 1996.

[30] LÓPEZ-CUELLAR, M.R., ALBA-FLORES, J., RODRÍGUEZ J.N.G., et al. "Production of polyhydroxyalkanoates (PHAs) with canola oil as carbon source", International Journal of Biological Macromolecules, v. 48, n. 1, pp. 74- 80, 2011.

[31] BHUWAL, A.K., SINGH, G., AGGARWAL, N.K., et al., "Isolation and Screening of Polyhydroxyalkanoates Producing Bacteria from Pulp, Paper, and Cardboard Industry Wastes", International Journal of Biomaterials, v. 2013, n. 1, pp. 1 -10, 2013.

[32] TÃNASE, E.E., POPA, M.E., RÂPÃ, M., et al., "PHB/Cellulose fibers based materials: physical, mechanical and barrier properties", Agriculture and Agricultural Science Procedia, v 6, n. 1, pp. 608 - 615, 2015.

[33] WANG, C., HSU, C.H., HWANG, I.H., "Scaling laws and internal structure for characterizing electro spun poly[(r)-3-hydroxybutyrate] fibers", Polymers. n. 49, pp. 4188-4195, 2008.

[34] MACHADO, M.L.C. PEREIRA, N.C., MIRANDA L.F., et al., "Estudo das propriedades mecânicas e térmicas do polímero poli-3-hidroxibutirato (PHB) e de compósitos PHB/pó de madeira", Polímeros: Ciência e Tecnologia, v. 20, n. 1, pp. 65- 71, 2010.

[35] HAHN, S.K., CHANG, Y.K., LEE, S.Y., "Recovery and characterization of poly(3-hydroxybutyric acid) synthesized in Alcaligenes eutrophus and recombinant Escherichia coli", Applied and Environmental Microbiology. v. 61, n. 1, pp. 34-39, 1995.

[36] BYRDSON, J. A. Plastics Materials. 6 ed. London: British Library Cataloguing in Publication Data, 1995.

[37] CANEVAROLO JR., S. V. Tecnicas de caracterização de polímeros. São Paulo: ArtLiber, 2004.

[38] MOUSAVIOUN, P., DOHERTY, W.O.S., GRAEME, G., "Thermal stability and miscibility of poly (hydroxybutyrate) and soda lignin blends". Industrial Crops and Products, v. 32, n. 3, pp. - 662, 2010.

[39] WELLEN, R.M.R. RABELLO M.S., ARAUJO JÚNIOR I.C., et al. "Melting and crystallization of poly (3-hydroxybutyrate): effect of heating/cooling rates on phase transformation", Polímeros, v. 25, n. 3, pp. 296304, 2015.

\section{ORCID}

Luana Orlandi de Aguiar

Natalício Stachewski

Michele Cristina Formolo Garcia

Ana Paula Kurek

Andrea Lima dos Santos Schneider

Denise Monique Dubet da Silva Mouga

Ana Paula Testa Pezzin https://orcid.org/0000-0002-2946-2888

https://orcid.org/0000-0002-1644-3645

https://orcid.org/0000-0002-6899-1264

https://orcid.org/0000-0002-5938-1173

https://orcid.org/0000-0002-2043-0177

https://orcid.org/0000-0002-0695-0467

https://orcid.org/0000-0001-9343-3929 